\title{
Thermal Aging Behaviors of Rubber Vulcanizates Cured with Single and Binary Cure Systems
}

\author{
Sung-Seen Choi, ${ }^{*}$ Sung-Ho Ha, and Chang-Su Woo ${ }^{\dagger}$ \\ Department of Applied Chemistry, Sejong University, Seoul 143-747, Korea. *E-mail: sschoi@sejong.ac.kr \\ ${ }^{\dagger}$ Korea Institute of Machinery and Materials, P.O. Box 101, Yusong, Daejeon 305-600, Korea \\ Received December 13, 2005
}

Key Words : Thermal aging, Crosslink density, Single cure system, Binary cure system, Rubber vulcanizate

Rubber compounds are crosslinked by a sulfur, peroxide, or resole cure system..$^{1-3}$ The sulfur vulcanization is the most popular method. In general, an accelerated sulfur cure system consists of elemental sulfur $\left(\mathrm{S}_{8}\right)$, one or two cure accelerators, and cure activators. Crosslink density of a rubber vulcanizate determines the physical properties. ${ }^{4}$ By increasing the crosslink density, the modulus, hardness, resilience, and abrasion resistance increase, whereas the elongation at break, heat build-up, and stress relaxation decrease.

Sulfur linkages are composed of monosulfide, disulfide, and polysulfides. Sulfur linkages, especially polysulfides, are dissociated by heating ${ }^{5-7}$ and this brings about decrease of the crosslink density. Curatives remained in a rubber vulcanizate make new crosslinks ${ }^{7,8}$ and this results in increase of the crosslink density. Crosslink density of a rubber vulcanizate is changed by thermal aging. ${ }^{9-12}$ In general, crosslink density of a sulfur-cured rubber vulcanizate increases with increase of the aging temperature. ${ }^{9-11}$ However, for a rubber vulcanziate with an elemental sulfur-free cure system, the crosslink density after thermal aging at high temperatures decreased. ${ }^{12}$ In the present work, we studied the thermal aging behaviors of the rubber vulcanizates with single and binary cure systems which have one and two cure accelerators, respectively. The single cure system had one cure accelerator of $N$-tert-butyl-2-benzothiazole sulfenamide (TBBS) and binary cure system had two cure accelerators

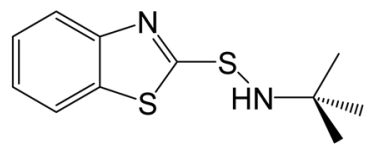

TBBS

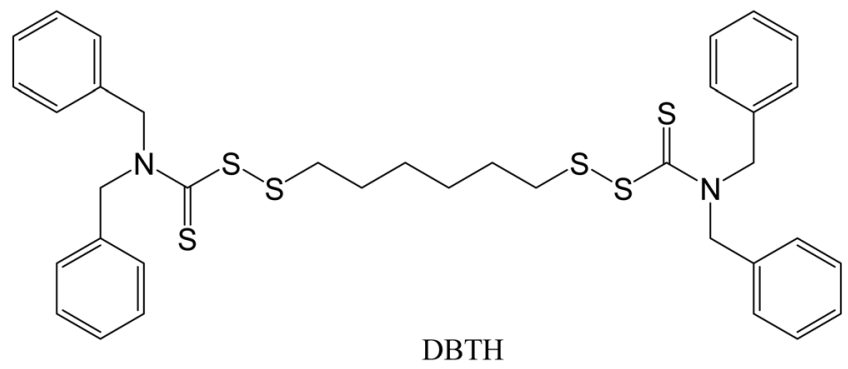

Scheme 1. Chemical structures of the cure accelerators. of TBBS and 1,6-bis( $N, N^{\prime}$-dibenzylthiocarbamoyldithio)hexane (DBTH). Scheme 1 shows the chemical structures of TBBS and DBTH. The binary cure system has faster cure rate and better reversion resistance than the single cure system. $^{13}$

The NR vulcanizates with different crosslink densities were prepared to investigate the influence of the initial crosslink density on the thermal aging behaviors. The aging temperatures $\left(50-90{ }^{\circ} \mathrm{C}\right.$ ) and aging times (4 and 8 days) were also varied to investigate the influence of the aging temperature and time on the thermal aging behaviors. Figures 1 and 2 show variations of the crosslink density changes by the thermal aging as a function of the aging temperature. The crosslink density change was calculated by dividing the difference in the crosslink densities of the vulcanizates after and before the thermal aging by the initial crosslink density; $\Delta \mathbf{X}_{\mathbf{c}}(\%)=100 \times\left(\mathbf{X}_{\mathbf{c}}{ }^{\text {aged }}-\mathbf{X}_{\mathbf{c}}{ }^{\text {ini }}\right) / \mathbf{X}_{\mathbf{c}}{ }^{\text {ini }}$, where the $\mathbf{X}_{\mathbf{c}}{ }^{\text {aged }}$ and $\mathbf{X}_{\mathbf{c}}{ }^{\text {ini }}$ indicate the crosslink densities of the vulcanizates after and before the thermal aging, respectively.

The crosslink densities after the thermal aging at $50-90{ }^{\circ} \mathrm{C}$ on the whole increased. The increased crosslink density after

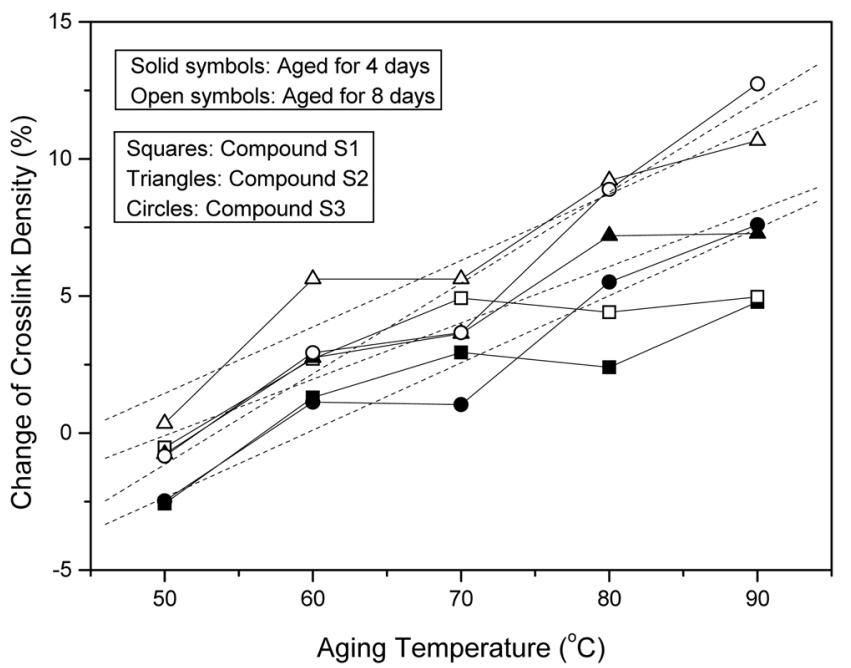

Figure 1. Variations of the crosslink density changes of the NR vulcanizates with the single cure systems (S1-S3) by the thermal aging with the aging temperature. The squares, triangles, and circles indicate the compounds S1, S2, and S3, respectively. The solid and open symbols stand for the aging time of 4 and 8 days, respectively. 


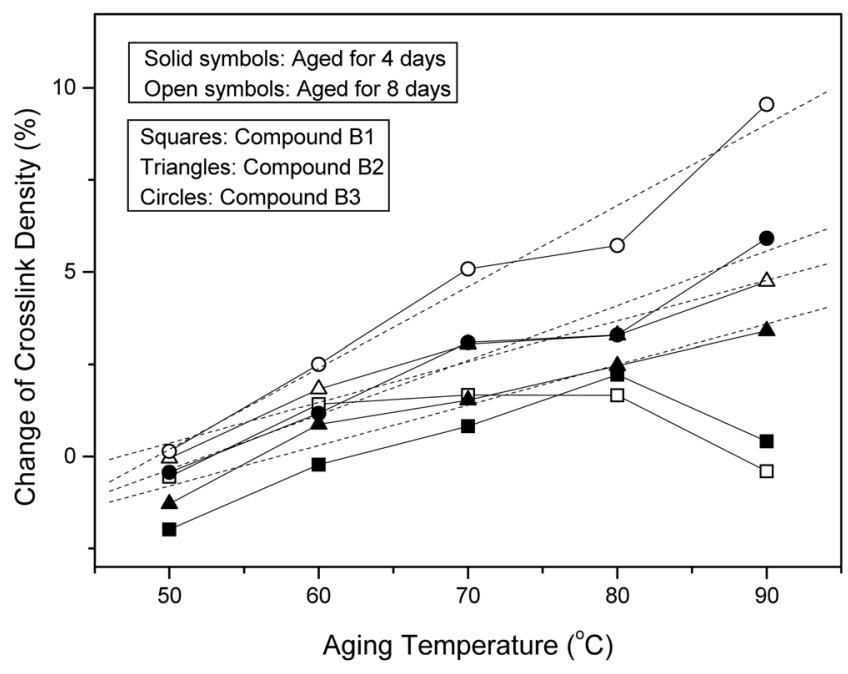

Figure 2. Variations of the crosslink density changes of the NR vulcanizates with the binary cure systems (B1-B3) by the thermal aging with the aging temperature. The squares, triangles, and circles indicate the compounds B1, B2, and B3, respectively. The solid and open symbols stand for the aging time of 4 and 8 days, respectively.

the thermal aging can be explained with the formations of new crosslinks by free curative residues such as elemental sulfur, cure accelerator residues, and zinc complexes remained in the vulcanizate. ${ }^{8,10,14,15}$ Especially, free sulfur remained in the vulcanizate reacts well with rubber chains and makes new crosslinks. ${ }^{8}$ A pendent sulfide group terminated by an accelerator residue reacts with another pendent group of the neighboring rubber chains, so a new crosslink will be formed. ${ }^{10,14,15}$ The crosslink density change on the whole increases as the aging temperature increases as shown in Figures 1 and 2. For the vulcanizates S1 and B1, the crosslink density changes increase and then decrease with increase of the aging temperature. The crosslink density changes of the vulcanizates S2, S3, B2, and B3 increase linearly as the aging temperature increases. The variations were well fitted with linear equations and the correlation
Table 2. Rates of the crosslink density changes obtained from the curve fittings of Figures 1 and $2\left(\% /{ }^{\circ} \mathrm{C}\right)$

\begin{tabular}{lcccc}
\hline Compound No. & S2 & S3 & B2 & B3 \\
\hline Aged for 4 days & 0.206 & 0.245 & 0.109 & 0.148 \\
Aged for 8 days & 0.242 & 0.331 & 0.110 & 0.220 \\
Difference & 0.038 & 0.086 & 0.001 & 0.072 \\
\hline
\end{tabular}

coefficients were $0.96-0.98$. Rates of the crosslink density changes were obtained from the linear curve fittings and were summarized in Table 2. The change rates of the vulcanizates with the single cure systems (S2 and S3) are much larger than those with the binary ones (B2 and B3). This implies that the crosslink density changes of the vulcanizates having the single cure systems (S-vulcanizates) depending on the aging temperature are bigger than the vulcanizates having binary cure systems (B-vulcanizates). The big difference in the crosslink density change rates of the S- and B-vulcanizates may be due to the curing efficiencies and the amount of the curative residues remained in the samples.

The B-vulcanizates can have more monosulfide linkages than the S-vulcanizates because of DBTH. DBTH is dissociated by heat so two dibenzyl carbamate radicals $(\mathrm{DBzCR})$ and one 1,6-hexanedithiol radical (HDTR) are generated as shown in Scheme 2. The HDTR reacts with two rubber chains to form monosulfide linkage. The B-vulcanizates have higher apparent crosslink densities $(\mathbf{1} / \mathbf{Q})$ than the S-vulcanizates although total sulfur contents of the Bcompounds are lower than those of the S-compounds. Curing efficiency was calculated by dividing the apparent crosslink density by the total sulfur content. The Bvulcanizates also have higher cure efficiencies than the Svulcanizates. The $\mathbf{1 / Q}$ values, the total sulfur contents, and the curing efficiencies were listed in Table 1. Amounts of the curative residues remained in the $\mathrm{S}$-vulcanizates will be larger than the B-ones. The larger amounts of the curative residues remained in the samples can lead to larger increase

Table 1. Formulations (phr)

\begin{tabular}{|c|c|c|c|c|c|c|}
\hline Compound No. & S1 & S2 & S3 & B1 & B2 & B3 \\
\hline SMR20 & 100.0 & 100.0 & 100.0 & 100.0 & 100.0 & 100.0 \\
\hline N330 & 50.0 & 50.0 & 50.0 & 50.0 & 50.0 & 50.0 \\
\hline Stearic acid & 2.0 & 2.0 & 2.0 & 2.0 & 2.0 & 2.0 \\
\hline $\mathrm{ZnO}$ & 4.0 & 4.0 & 4.0 & 4.0 & 4.0 & 4.0 \\
\hline HPPD & 2.0 & 2.0 & 2.0 & 2.0 & 2.0 & 2.0 \\
\hline Wax & 2.0 & 2.0 & 2.0 & 2.0 & 2.0 & 2.0 \\
\hline Sulfur & 1.0 & 1.4 & 1.8 & 0.8 & 1.0 & 1.2 \\
\hline TBBS & 1.0 & 1.4 & 1.8 & 0.5 & 0.5 & 0.5 \\
\hline DBTH & 0.0 & 0.0 & 0.0 & 0.5 & 0.9 & 1.3 \\
\hline Total sulfur content (wt $\%)$ & 0.70 & 0.98 & 1.25 & 0.62 & 0.81 & 1.00 \\
\hline Apparent crosslink density (1/Q) & 0.88 & 1.02 & 1.19 & 0.93 & 1.08 & 1.35 \\
\hline Curing efficiency (wt $\%^{-1}$ ) & 1.26 & 1.04 & 0.95 & 1.50 & 1.33 & 1.35 \\
\hline
\end{tabular}

HPPD: $N$-phenyl- $N$ '-(1,3-dimethylbutyl)-p-phenylenediamine. TBBS: $N$-tert-butyl-2-benzothiazole sulfenamide. DBTH: 1,6-bis( $N, N$ '-dibenzylthiocarbamoyldithio)-hexane 
<smiles>CSC(=S)N(Cc1ccccc1)Cc1ccccc1</smiles><smiles>CCCCCSC</smiles><smiles>CSC(=S)N(Cc1ccccc1)Cc1ccccc1</smiles><smiles>[SiH3]CCCCCCC[S-]</smiles>

Rubber<smiles>[R][R7]([H])([H])[H]</smiles>

Scheme 2. Formation of monosulfide crosslink by DBTH.

of the crosslink density change by the thermal aging.

The B-vulcanizates have also more stable thermal aging behaviors depending on the aging time. Difference in the crosslink density change rates of the thermal aging for 4 and 8 days for the B-vulcanizates is smaller than for the Svulcanizates as listed in Table 2 . This can be also explained with the remained curative contents and the stabilities of sulfide linkages. The B-vulcanizates have more stable linkages and lower contents of the remained curative residues as discussed previously. Thus, the crosslink density changes of the B-vulcanizates by the thermal aging will be lower than those of the S-ones. According to the experimental results, it can lead to a conclusion that the vulcanizates cured with the binary cure systems have better curing efficiencies and better thermal aging resistances compared to the vulcanizates cured with the single cure systems

\section{Experimental Section}

The NR compounds were made of NR (SMR 20), carbon black (N330), cure activators (stearic acid and $\mathrm{ZnO}$ ), antidegradants (HPPD and wax), and curatives (TBBS, DBTH, and sulfur). The formulations were given in Table 1 . The compounds S1, S2, and S3 have single accelerator cure systems of TBBS, while the compounds B1, B2, and B3 have binary accelerator cure systems of TBBS and DBTH. Contents of the curatives were varied to prepare the samples with different crosslink densities.

The vulcanizates were prepared by curing at $160{ }^{\circ} \mathrm{C}$ for 20 min. Thermal aging was performed at 50, 60, 70, 80, and 90 ${ }^{\circ} \mathrm{C}$ for 4 and 8 days in a convection oven. Crosslink densities of the samples were measured by swelling method. Organic additives in the samples were removed by extracting with THF and $n$-hexane for 3 and 2 days, respectively, and they were dried for 2 days at room temperature. The weights of the organic materials-extracted samples were measured.
They were soaked in $n$-decane for 2 days and the weights of the swollen samples were measured. The swelling ratio $(\mathbf{Q})$ was calculated by the equation of $\mathbf{Q}=\left(\mathbf{W}_{\mathbf{s}}-\mathbf{W}_{\mathbf{u}}\right) / \mathbf{W}_{\mathbf{u}}$, where $\mathbf{W}_{\mathbf{s}}$ and $\mathbf{W}_{\mathbf{u}}$ are weights of the swollen and unswollen samples. In general, the reciprocal swelling ratio $(\mathbf{1} / \mathbf{Q})$ was used as the apparent crosslink density. Experiments were carried out three times and they were averaged.

Acknowledgements. This research has been supported by Reliability Design Technology Program (grant no. M10401000005) of Ministry of Science and Technology, Korea.

\section{References and Notes}

1. Krejsa, M. R.; Koenig, J. L. Rubber Chem. Technol. 1993, 66, 376.

2. Chakraborty, S. K.; Bhowmick, A. K.; De, S. K. J. Macromol. Sci.-Rev. Macromol. Chem. 1981-82, C21, 313.

3. van Duin, M.; Souphanthong, A. Rubber Chem. Technol. 1995, $68,717$.

4. Morrison, N. J.; Porter, M. Rubber Chem. Technol. 1984, 57, 63.

5. Chen, C. H.; Koenig, J. L.; Shelton, J. R.; Collins, E. A. Rubber Chem. Technol. 1981, 54, 734.

6. Choi, S.-S. Kor. Polym. J. 1997, 5, 39.

7. Choi, S.-S. Bull. Kor. Chem. Soc. 2000, 21, 628.

8. Layer, R. W. Rubber Chem. Technol. 1992, 65, 211.

9. Choi, S.-S. Kor. Polym. J. 1999, 7, 108.

10. Choi, S.-S. J. Appl. Polym. Sci. 2000, 75, 1378.

11. Choi, S.-S. Polym. Int. 2001, 50, 107.

12. Choi, S.-S.; Han, D.-H.; Ko, S.-W.; Lee, H. S. Bull. Kor. Chem. Soc. 2005, 26, 1853.

13. Choi, S.-S.; Park, B.-H.; Lee, S. G..; Kim, B. T. Bull. Kor. Chem. Soc. 2002, 23, 320.

14. Gradwell, M. H. S.; McGill, W. J. J. Appl. Polym. Sci. 1996, 61, 1131.

15. Gradwell, M. H. S.; McGill, W. J. J. Appl. Polym. Sci. 1996, 61, 1515. 